\title{
BEIJAR E MATAR, PENA MÍNIMA DE SEIS ANOS DE RECLUSÃO: a teratológica legislação criminal de condutas indeterminadas
}

\author{
André Luis Callegaro Nunes ${ }^{1}$
}

\begin{abstract}
Resumo: A hediondez do delito de atentado violento gera o perigo de se igualarem as penas mínimas aplicadas ao sujeito que pratica um simples "ato libidinoso" e aquele que "mata alguém". A conduta descrita no art. 214 do Código Penal não atenta para o fato que o ato libidinoso se amolda a qualquer conduta, ensejando interpretações ofensivas a princípios constitucionais. Neste ponto a legislação penal não mantém o equilíbrio entre o fato narrado e a aplicação da sanção. Viola a isonomia, punindo com a mesma sanção indivíduos que se encontram em situações diversas e ignora a proporcionalidade da resposta estatal, podendo ofender o princípio da insignificância. Diante disso, para manter hígidos os pilares da isonomia e proporcionalidade propõe-se a isenção ou diminuição da responsabilidade penal do acusado a fim de que se tenha uma adequada a sanção estatal para cada conduta delitiva.
\end{abstract}

Palavras Chaves: atentado violento ao pudor - insignificância - desclassificação - contravenção.

Review: the hideousness of the crime of the violent attempt triggers the danger of considering the same the minimum punishment applied to the person who practices a simple "libidinous act" and another one who "kills someone". The conduct described in the art. 214 of the Penal Code does not notice to the fact that the libidinous act molds itself to any conduct, presenting offensive interpretations to constitutional principles. In this point, the penal legislation does not keep on the balance between the related fact and the sanction application. It violates the isonomy, punishing with the same sanction people who are in diverse situations and it ignores the proportionality of the state's answer, which can offend the insignificance principle. Observing these facts, to keep on salutary the pillars of the isonomy and the proportionality, it is proposed either the exemption or the decrease of the penal responsibility of the accused person in order to have an adequate state sanction to each delictive conduct.

KEY-WORDS: violent attempt against someone's modesty - insignificance - disclassification contravention

Com o advento da lei dos crimes hediondos (Lei $\left.\mathrm{n}^{\circ} 8.072 / 90\right)$ foi elevada a pena cominada para o delito de atentado violento ao pudor, fixando o mínimo de 06 (seis) e o máximo de 10 (dez) anos de reclusão. A maior gravidade das sanções dos crimes hediondos faz jus a maior gravidade dos atos sexuais diversos da conjunção carnal, como sexo anal e oral. De modo que quanto maior a gravidade do fato maior será a reprimenda, em obediência ao princípio da razoabilidade ou proporcionalidade entre a conduta e a sanção.

Em atenção ao conceito de bem jurídico ancorado ao texto constitucional, deve ser mantido o equilíbrio concreto entre a aplicação de sanção e o fato narrado sob pena de perpetrar-se uma anomalia jurídica, ou seja, admitir que no Brasil, beijar (ainda que

\footnotetext{
1 Advogado Graduado em Direito pelaUFSM e especializado em Ciências Penais pela rede de ensino LFG/IDRS. E-mail para contato: andrelcngomes@hotmail.com.
}

ISSN - 1981-3694

(C) 2007. Departamento de Direito da UFSM. Todos os direitos reservados. 
lascivamente) e matar alguém possuem a mesma pena mínima cominada, (06) seis anos de prisão.

Tal problema trazido à tona pelo legislador em com a promulgação da Lei dos Crimes Hediondos que elevou a pena do delito de atentado violento ao pudor, art. 214 do CP, sem atentar para o fato de que a conduta incriminada como "ato libidinoso" se amolda a qualquer conduta. Assim, o texto legal acaba por permitir interpretações permeadas de conceitos morais e com diferentes graus de lesividade ao bem jurídico.

Num Estado Democrático de Direito as leis penais limitam o indivíduo em sua liberdade de agir, mas não se proíbe além do necessário e suficiente para que se alcance uma co-existência livre e pacífica. É feita uma autolimitação para garantir os direitos e garantias fundamentais como mecanismo de contenção ao arbítrio do próprio Estado. Para ROXIN (2004):

(...) deve-se ter em mente que essas considerações excluem de antemão vários conceitos do direito penal que foram por bastante tempo dominantes e ainda hoje exercem grande influência. Por ex., não é permitido deduzir proibições de direito penal dos princípios de uma certa ética. Pois, em primeiro lugar, nem todo comportamento eticamente reprovável perturba a convivência entre os homens. E, em segundo lugar, muitos princípios éticos são questão de crença, que não podem ser impostos ao indivíduo. CLAUS ROXIN (2004)

Por isso, anota PRADO (1996, p. 65): “nesse contexto, a noção de bem jurídico emerge dentro de certos parâmetros gerais de natureza constitucional, capazes de impor uma certa e necessária direção restritiva ao legislador ordinário, quando da criação do injusto penal."

A amplitude de condutas descritas no tipo penal contraria o princípio da isonomia e proporcionalidade.

O princípio da isonomia tem como destinatário tanto o legislador quanto o aplicador da lei. O legislador é o destinatário principal do princípio da isonomia, e significa, segundo lição de FAGUNDES (2004 apud SILVA, 2004, p.214): “que, ao elaborar a lei, deve reger, com iguais disposições - os mesmos ônus e as mesmas vantagens - situações idênticas, e, reciprocamente, distinguir, na repartição de encargos e benefícios, as situações que sejam entre si distintas, de sorte a quinhoá-las ou gravalas em proporção às suas diversidades."

A isonomia é rompida porque a pena mínima abstratamente cominada ao delito de atentado violento ao pudor gera sério risco de apenar indivíduos que se encontram 
em situações distintas, e.g., é evidente que a conduta de dar um beijo lascivo não pode e nunca será tão grave quanto a conduta de um indivíduo que força um ato de felação. Não há margem para um julgamento justo, vez que a lei impõem a ambos a pena mínima de seis anos de reclusão.

Por sua vez, a proporcionalidade consoante HASSEMER (1984 apud PRADO, 2004, p. 143) expressa "uma concordância material entre a ação e a reação, causa e consequiência, delito e consequiência jurídico-penal. Constituindo parte do postulado de Justiça: ninguém pode ser incomodado ou lesionado em seus direitos com medidas jurídicas desproporcionadas."

A proporcionalidade é ferida quando a resposta estatal a fatos menores é representada por uma sanção que, em tese, pode se aproximar ou igualar a sanção imposta ao homicídio simples, cuja pena mínima é de 06 (seis) anos.

Embora inegável a anomalia antes constatada, resta ao operador do direito encontrar uma solução plausível, já que de nada adianta aguardar a improvável redução da pena pelo Poder Legislativo.

O primeiro passo, conforme ROXIN (2004):

é reconhecer que injusto e responsabilidade se tratam de diversas valorações, que devem ser referidas cada qual a um substrato próprio. $O$ injusto determina o que é proibido sob ameaça de pena, que comportamento é portanto, legal ou ilegal. Já a responsabilidade decide quais dentre os comportamentos ilícitos necessitam de pena e em quais deles a pena deve ser dispensada. $O$ primeiro nível é valorativo tem por tarefa o controle de comportamentos: ele diz aos cidadãos o que, segundo as regras do direito penal, devem omitir e, em certos casos, fazer, combinando uma valoração com uma diretriz de comportamento. O segundo nível decide a respeito da conseqüência jurídica - punibilidade ou não-punibilidade - segundo pontos de vista que não se confundem, de modo algum, com os da valoração do injusto, mas que devem ser extraídos da teoria dos fins da pena. ROXIN (2004)

O problema criado pelo legislador ordinário com a elevação da pena cominada ao crime de atentado violento ao pudor situa-se no âmbito do injusto. Porém, felizmente a solução se situa no campo da responsabilidade penal.

A responsabilidade penal pode ser diminuída ou mesmo inexistente se o magistrado tiver como norte um novo discurso jurídico, um discurso jurídico dinâmico e garantidor dos direitos e garantias constitucionais. Para isso a Carta Magna figura como parâmetro de verificação da validade das normas infraconstitucionais. 
Desta forma, uma opção constitucional é a absolvição com fulcro no princípio da insignificância, que espelha uma política criminal de intervenção mínima. Exalta-se o caráter fragmentário do Direito Penal, que implica condicionar a intervenção estatal no seu viés punitivo à existência de relevante lesão ou perigo de lesão ao bem jurídico tutelado. Como desdobramento dessa característica conclui-se que é insignificante a conduta ou resultado que não ofenda, ao menos em tese, o bem jurídico penalmente tutelado. A insignificância assenta-se no brocardo de minimis non curat praetor e na conveniência da política criminal, portanto, nos casos em que o delito de atentado violento ao pudor for incapaz de ofender a liberdade sexual concretamente, não haverá como enquadrá-lo no tipo ensejando a absolvição.

Outra alternativa para se evitar tamanha desproporcionalidade na aplicação da pena é desclassificar o fato incriminado como atentado violento para o crime de ato obsceno (art.233, CP) ou a contravenção penal de importunação ofensiva ao pudor (art.61, LCP), por possuírem menor danosidade. Nestas infrações penais, a conduta apenas contrasta com o sentimento médio de pudor ou bons costumes, tais como apalpadelas nos seios, nas nádegas, toques no corpo da vítima ou mesmo um beijo lascivo etc. Motivo pelo qual, em atenção ao princípio da proporcionalidade, a reprimenda imposta pelo Estado-Juiz deve ser menor. Não sendo assim, a resposta estatal a tais fatos menores poderá, em tese, aproximar-se dos igualar-se a sanção imposta ao homicídio simples, cuja pena mínima é de 06 (seis) anos.

Menciona BITENCOURT (2005, p. 870), que “essa interpretação é recomendável e autorizada pelo princípio da proporcionalidade, não se podendo ignorar o desnível que tais condutas apresentam em relação não só ao desvalor da ação como também ao desvalor do resultado, comparadas com sexo anal ou oral, exigindo, por isso, menor severidade na sua representação (proporcional)."

A jurisprudência, por seu turno, compartilha o mesmo entendimento, vejamos os seguintes julgados:

Atentado violento ao pudor. Réu que passa a mão nas nádegas da vítima. Ausência de atos inequívocos dirigidos ao fim libidinoso. Agente que profere palavras libertinas ao ofendido. Conduta desnudada de concupiscência. Conjunto probatório que determina a desclassificação do art. 214, do CP para a contravenção de perturbação da tranqüilidade. Emendatio libelli que se impõe.

"Não se confunde a prática de ato libidinoso com as contravenções dos arts. 61 e 65 da LCP. Nestas, o agente pratica ato que contrasta com o sentimento 
médio de pudor ou bons costumes, como beijos ligeiros, apalpadelas, toques no corpo etc., e naquele é necessário o ato concupiscente. É indispensável, para a caracterização do atentado violento ao pudor, o contato físico entre o agente e a vítima; não ocorrendo este, poderá caracterizar-se outro ilícito: constrangimento ilegal, corrupção de menor, crime contra criança ou adolescente, ato obsceno, importunação ofensiva ao pudor, etc." (Júlio Fabbrini Mirabete). (...) Recurso parcialmente provido.(Apelação Criminal (Réu Preso) $n^{o}$ 2004.032914-6, $1^{a}$ Câmara Criminal do TJSC, Fraiburgo, Rel. Des. Carstens Köhler. unânime, DJ 18.03.2005).

Crime contra os costumes. Atentado violento ao pudor. Palavra da vítima obtida somente no inquisitório. Conjunto probatório dos autos. Certeza da autoria. Simples toques nos seios da ofendida. Incidência do princípio da proporcionalidade. Desclassificação. Possibilidade.

(...)

2. Fere o princípio da proporcionalidade o mesmo apenamento ao estupro, ao atentado violento ao pudor sem qualquer espécie de cópula e a prática de atos libidinosos menos graves: beijo lascivo, apalpadela, toque nos seios, etc.

3. Os delitos de estupro e atentado violento ao pudor possuem igual apenamento: 6 a 10 anos de reclusão. O legislador de 1990 não considerou no processo de tipificação criminal o princípio da proporcionalidade. Assim, por exemplo, manter conjunção carnal ou outro tipo de relação sexual, bem como qualquer ato libidinoso diverso da conjunção carnal, por mais simples que seja, tem a mesma reprovabilidade jurídica.

4. No caso em tela, a proporcionalidade indica o apenamento pelo delito corrupção de menor.

Apelo defensivo parcialmente provido. (Apelação-Crime $n^{o} 70011222296,7^{a}$ Câmara Criminal do TJRS, Erechim, Rel. Des. Nereu José Giacomolli. j. 16.06.2005, unânime).

Tomando-se em conta tudo o que foi dito, à primeira vista podemos lamentar o fato que a lei vigente permite agride direitos fundamentais do cidadão, como a isonomia e a proporcionalidade. Derrotado pela legalidade o magistrado passaria a reproduzir o texto legal, afinal a legalidade é princípio basilar do Estado Democrático de Direito e das decisões judiciais, devem se fundar na lei.

Todavia, numa outra perspectiva, antes de se resignar aos ditames legais, faz-se necessário saber que o império da lei somente se justifica se essa lei buscar a igualdade e a justiça no caso concreto, se se propõe a melhorar a realidade daqueles que são o titular do poder: o povo.

Neste sentido, a Constituição Federal estabelece as bases da legalidade, informando os valores a serem respeitados pela sociedade. De forma que tais valores sevem de parâmetro a atividade estatal, submetendo o Estado (qualificado de Democrático e de Direito) à Constituição. É ela, a Constituição, que regula a atividade 
punitiva do Estado e por isso impõe limitações ao legislador mediante direitos fundamentais.

Destarte, a atividade estatal está submetida à uma legalidade maior determinada

pela Constituição. Assim, num traçado constitucional pode-se buscar a proporcionalidade e a isonomia ao impor a responsabilidade penal. Nos casos de prática de atos libidinosos menos graves, como um beijo lascivo, a responsabilidade penal pode ser inexistente, sendo o acusado absolvido em razão do princípio da insignificância se o delito de atentado violento ao pudor não ofender concretamente a liberdade sexual. Outrossim, a responsabilidade penal poder ser reduzida em face da desclassificação do fato incriminado como atentado violento para infrações penais com sanções menores, como a do ato obsceno ou a da contravenção penal de importunação ofensiva ao pudor. Essas são as vias ofertadas pela atual legislação penal para se evitar que no Brasil beijar e matar recebam idênticas penas mínimas.

\section{REFERÊNCIAS BIBLIOGRÁFICAS}

BITENCOURT, Cezar Roberto. Código de Direito Penal Comentado. $3^{a}$ ed. São Paulo: Saraiva, 2005.

CLAUS, Roxin. Que comportamentos pode o Estado proibir sob ameaça de pena? Sobre a legitimação das proibições penais. Texto distribuído aos inscritos no seminário ocorrido em Porto Alegre, nos dias 18 a 20 de março de 2004, em homenagem ao Professor Claus Roxin, de Direito Penal Econômico, organizado pelo Prof. Cezar Roberto Bitencourt.

. Normativismo, política criminal e dados empíricos na dogmática do direito penal. Texto distribuído aos inscritos no seminário ocorrido em Porto Alegre, nos dias 18 a 20 de março de 2004, em homenagem ao Professor Claus Roxin, de Direito Penal Econômico, organizado pelo Prof. Cezar Roberto Bitencourt.

PRADO, Luiz Regis. Bem Jurídico-Penal e Constituição. São Paulo: Editora Revista dos Tribunais, 1996.

dos Tribunais, 2004.

Curso de Direito Penal Brasileiro. $4^{\circ}$ ed. São Paulo: Revista

SILVA, José Afonso da. Curso de Direito Constitucional Positivo. $23^{\circ}$ ed., revista e atualizada nos termos da Reforma Constitucional (até a Emenda Constitucional $\mathrm{n}^{\circ} 42$, de 19.12.2003), São Paulo: Malheiros Editores, 2004. 